Annals of Pure and Applied Mathematics

Vol. 16, No. 1, 2018, 105-116

ISSN: 2279-087X (P), 2279-0888(online)

Published on 2 January 2018

www.researchmathsci.org

DOI: http://dx.doi.org/10.22457/apam.v16n1a12

Annals of

Pure and Applied

Mathematics

\title{
An Inventory Model for Deteriorating Items with Non-Linear Selling Price Dependent Demand and Exponentially Partial Backlogging Shortage
}

\author{
M. Golam Arif \\ Institute of Business Administration, University of Rajshahi \\ Rajshahi-6205, Bangladesh \\ Email: mgarif_iba_ru@yahoo.com \\ Received 3 November 2017; accepted 2 December 2017
}

\begin{abstract}
In this paper, we have developed an inventory models for deteriorating items with non-linear price dependent demand and frequency of advertisement of items. It is allowed and partially backlogged with a exponential rate on the duration of waiting time up to the arrival of next lot. In this model, the deterioration rate follows three-parameter weibull distribution and the transportation cost is considered explicitly for replenishing the order quantity. The transportation cost is dependent on the lot-size as well as the distance from the source to the destination of the located shop. The corresponding nonlinear model are formulated and solved by considering the transportation cost for replenishing the items. A numerical example is given to illustrate the results and the significant features of the result are discussed. Finally, we have performed the sensitivity analysis taking one or more parameters at a time.
\end{abstract}

Keywords: EOQ model, Deterioration, Weibul distribution, non-linear price dependent demand, Partially backlogged shortage

\section{AMS Mathematics Subject Classification (2010): 90B05}

\section{Introduction}

In the existing literature of inventory, generally most of the researchers have developed the inventory model under the assumption that the life time of an item is infinite while it is in storage i.e., an item once in stock remains unchanged and fully usable for satisfying future demand of the customers. But in reality, this assumption is not always true due to the effect of deterioration in the preservation of commonly used physical goods and these goods are not in a perfect condition to satisfy the customer demand. As a result, the loss due to this natural phenomenon (i.e., the deterioration effect) can't be ignored in the analysis of the inventory system. Ghare and Schrader [1] first introduce these concepts and developed an inventory model for exponentially decaying inventory. Then Emmons [2] proposed this type of model with variable deterioration which follows two-parameter weibull distribution. These models were extended and improved by several researchers, viz. Covert and Philip [3], Giri et al. [4], Ghosh and Chaudhari [5]. On the other hand, Chakrabarty et al. [6], Giri et al.[7], Sana et al. [8], Sana and Chaudhari [9] and others 


\section{Golam Arif}

developed inventory models for deteriorating items with there-parameter weibull distributed deterioration. Misra [10] developed an EOQ model with a weibull deterioration rate for perishable product without considering backlogging situation. These investigations were followed by several researchers like, Deb and Chaudhari [11], Giri et al. [12], Goswami and Chaudhari [13], Mandal and Phaujdar [14], Padmanabhan and Vrat [15], Pal et al. [16], Mandal and Maiti [17], Goyal and Gunasekaran [18], Sarkar et al.[19], Bhunia and Maiti [20,21], Bhunia and Shaikh [22,23,24], Pal et al. [25], Bhunia et al. [26], Bhunia and Shaikh [27], Bhunia et al [28], etc., where a time-proportional deterioration rate was considered. We also consider the work of Chakraborty, Pal and Nayek [48-52].

In the present competitive market, the effect of marketing policies and conditions such as the price variations and the advertisement of an item change its demand pattern amongst the public. The propaganda and canvassing of an item by advertisement in the well-known media such as Newspaper, Magazine, Radio, T.V., Cinema, etc. and also through the sales representatives have a motivational effect on the people to buy more. Also, the selling price of an item is one of the decisive factors in selecting an item for use. It is commonly seen that lesser selling price causes increase in demand whereas higher selling price has the reverse effect. Hence, it can be concluded that the demand of an item is a function of displayed inventory in a show-room, selling price of an item and the advertisement expenditures frequency of advertisement. Very few OR researchers and practitioners studied the effects of price variation and the advertisement on the demand rate of items. Kotler [29] incorporated marketing policies into inventory decisions and discussed the relationship between economic ordering quantity and pricing decision. Ladany and Sternleib [30] studied the effect of price variation on selling and consequently on EOQ. However, they did not consider the effect of advertisement. Subramanyam and Kumaraswamy [31], Urban [32], Abad [33] and Luo [34] developed inventory models incorporating the effects of price variations and advertisement on demand rate of an item. In this connection we may refer some recent works such as Shaikh [35], Bhunia et al. [36, 37, 38, 39], Bhunia and Shaikh [40], Shaikh et al. [41, 42, 43, 44], Bhunia et al. [45], Tiwari et al. [46], Mishra et al. [47], etc.

In this paper, we have developed an inventory model for deteriorating items with non-linear variable demand dependent on the selling price of items and frequency of advertisement. Shortages are allowed partially with a variable rate dependent on the duration of waiting time up to the arrival of next lot. In this model, the deterioration rate follows a three-parameter weibull distribution and the transportation cost is considered explicitly for replenishing the order quantity. In real-life situation, it is observed that a fixed cost is incurred for a transport mode such as truck, wagon. Therefore, the transportation cost is dependent on the lot-size as well as the distance from the source to the destination. The corresponding models are formulated and solved by considering the transportation cost for replenishing the items. A numerical example is considered to illustrate the model and the significant features of the result are discussed. Finally, based on these examples, we have performed a sensitivity analysis and make a fruitful conclusion.

\section{Assumptions and notations}

We have developed the paper by considering the following assumption as notations: 
An Inventory Model for Deteriorating Items with Non-Linear Selling Price Dependent Demand and Exponentially Partial Backlogging Shortage

\section{Assumption:}

(i) Replenishments are instantaneous.

(ii) Lead time is negligible.

(iii) The inventory planning horizon is infinite and the inventory system involves only one item.

(iv) The deterioration occurs when the item is effectively in-stock and the rate of deterioration follows a three-parameter weibull distribution.

(v) The deteriorated units are not replaced or not repaired.

(vi) The replenishment cost (ordering cost) is constant and does not include the transportation cost for replenishing the item.

(vii) The demand rate $D(A, p)$ is dependent on selling price $(p)$ of an item and the frequency of advertisement $(A)$. We assume it as follows:

$D(A, p)=A^{v} a p^{-b}, a, b, v \geq 0$.

(viii) $C_{t}$ be the transportation cost for full load of the transport vehicle and $C_{t F}$ be the transportation cost per unit item.

(ix) $U$ be the upper break point, some quantity loss than $k$ but more than $U$, the transportation cost for whole quantity is $C_{t}$.

Hence $U=\frac{C_{t}}{C_{t F}}(<k)$ where $\left[\frac{C_{t}}{C_{t F}}\right]$ represents the greatest integer value which is less then or equal to $C_{t} / C_{t F}$.

\section{Notations:}

\begin{tabular}{lll}
\hline Notations & Units & Description \\
$C_{o}$ & $\$ /$ order & Ordering cost \\
$a$ & Constant & Demand parameter $(a>0)$ \\
$b$ & Constant & Demand parameter $(b>0)$ \\
$p$ & $\$ /$ unit & Selling price per unit and it is denoted $p=m C_{\mathrm{p}}$ \\
$C_{p}$ & Units & Purchase cost per unit \\
$C_{l}$ & $\$ /$ unit & Opportunity cost per unit \\
$C_{b}$ & $\$$ unit & Shortage cost per unit \\
$C_{h}$ & $\$$ unit /unit time & Holding cost per unit \\
$R$ & Units & Maximum backlogged units \\
$S$ & Units & Maximum inventory level \\
$C_{a d}$ & $\$ /$ unit /unit time & Advertisement cost per advertisement \\
$A$ & unit & Frequency of advertisement \\
$L$ & Km & Be the distance between the shop and the source of \\
\end{tabular}


M. Golam Arif

items/commodities to be transported.

$n \quad$ unit Number of fully loaded vehicle.

$k \quad$ unit Capacity of the transport vehicle.

Z \$/year Total profit per unit time.

Decision variables

$t_{1} \quad$ Years Time at which the stock in RW reaches to zero

$T \quad$ Years The length of the replenishment cycle

\section{Mathematical model}

In this model, shortages are allowed and partially backlogged and backlogging rate is dependent on the length of the waiting time up to the arrival of fresh lot. By considering this situation, the rate is defined as $e^{-\delta(T-t)}, \delta>0$.

Initially, it is assumed that after fulfilling the backorder quantity, the on-hand inventory level is $S$ at $t=0$ and it declines continuously up to the time $t=t_{1}$ when it reaches the zero level. The decline in inventory during the closed time interval $0 \leq t \leq t_{1}$ occurs due to the customer's demand and deterioration of the item. After the time $t=t_{1}$, shortage occurs and it accumulates at the rate $e^{-\delta(T-t)},(\delta>0)$ up to the time $t=T$ when the next lot arrives. At time $t=T$, the maximum shortage level is $R$. This entire cycle then repeats itself after the cycle length $T$.

Let $q(t)$ be the inventory level at any time $t \geq 0$. Then the inventory level $q(t)$ at any time $t$ satisfies the differential equations

$$
\begin{gathered}
q^{\prime}(t)+\theta(t) q(t)=-D(A, p), \quad 0 \leq t \leq t_{1} \\
q^{\prime}(t)=-D(A, p) e^{-\delta(T-t)}, t_{1}<t \leq T
\end{gathered}
$$

with the boundary conditions

$q(t)=S$ at $t=0, q(t)=0$ at $t=t_{1}$.

and $q(t)=-R$ at $t=T$.

Also, $q(t)$ is continuous at $t=t_{1}$.

Using the conditions (3) and (4), the solutions of the differential equations (1)-(2) are given by

$$
\begin{aligned}
q(t) & =D(A, p) e^{-\alpha(t-\gamma)^{\beta}} \int_{t}^{t_{1}} e^{\alpha(t-\gamma)^{\beta}} d t, \quad 0 \leq t \leq t_{1} \\
& =\frac{D(A, p)}{\delta}\left\{1-e^{-\delta(T-t)}\right\}-R, \quad t_{1}<t \leq T
\end{aligned}
$$

From (2), we have $q(t)=S$ at $t=0$. 
An Inventory Model for Deteriorating Items with Non-Linear Selling Price Dependent Demand and Exponentially Partial Backlogging Shortage

Then, $S=D(A, p) e^{-\alpha(-\gamma)^{\beta}} \int_{0}^{t_{1}} e^{\alpha(t-\gamma)^{\beta}} d t$

From the continuity condition, we have

$$
R=\frac{D(A, p)}{\delta}\left\{1-e^{-\delta\left(T-t_{1}\right)}\right\}
$$

The total number of deteriorated units is given by

$$
D^{\prime}=\int_{0}^{T} \theta(t) q(t) d t
$$

The total inventory cost per cycle of the system consists of the following components and which given below:

(i) ordering cost, (ii) purchasing cost, (iii) inventory holding cost, (iv) advertisement cost, (v) transportation cost, (vi) shortage cost, (vii) opportunity cost.

Ordering cost: Since there is only one item and one stocking point, the ordering cost is $C_{o}$.

Purchasing cost: Since the ordering quantity per cycle is $S+R$, the total purchase cost is $C_{p}(S+R)$.

Inventory holding cost: The inventory holding cost per unit time is the product of the inventory level and holding cost per unit time. Thus the total inventory holding cost for the entire cycle is given by

$$
C_{h o l}=C_{h} \int_{0}^{t_{1}} q(t) d t
$$

where

$$
\begin{array}{r}
\int_{0}^{t_{1}} q(t) d t=\frac{t_{1}^{2}}{2}+ \\
\frac{\alpha^{2} t_{1}\left(t_{1}-\gamma\right)^{2 \beta+1}}{2(2 \beta+1)}-\frac{\alpha\left(t_{1}-\gamma\right)^{\beta+2}}{(\beta+1)(\beta+2)}-\frac{\alpha^{2}\left(t_{1}-\gamma\right)^{2 \beta+2}}{2(2 \beta+1)(2 \beta+2)} \\
+\frac{\alpha^{2}\left(t_{1}-\gamma\right)^{2 \beta+2}}{(\beta+1)^{2}}+\alpha(-\gamma)^{\beta}\left\{\frac{t_{1}^{2}}{2}-\left(\frac{\beta}{\gamma}\right) \frac{t_{1}^{3}}{3}\right\} \\
+\frac{\alpha(-\gamma)^{2 \beta+2}}{(\beta+1)(2 \beta+2)}+\frac{\alpha^{2} t_{1}\left(t_{1}-\gamma\right)^{2 \beta+1}}{2(2 \beta+1)}-\frac{\alpha^{2}(-\gamma)^{2 \beta}}{2}\left\{\frac{t_{1}^{2}}{2}-\left(\frac{2 \beta}{\gamma}\right) \frac{t_{1}^{3}}{3}\right\} \\
+\frac{\alpha^{2}(-\gamma)^{2 \beta+2}}{2(2 \beta+1)(2 \beta+2)}+\frac{\alpha t_{1}(-\gamma)^{\beta+1}}{(\beta+1)}(-\gamma)^{\beta+1}-\frac{\alpha^{2}(-\gamma)^{2 \beta+2}}{(\beta+1)(2 \beta+2)}-\frac{\alpha^{2} t_{1}(-\gamma)^{2 \beta+1}}{2(2 \beta+1)}
\end{array}
$$




\section{Golam Arif}

Advertisement cost: The total advertisement cost $C_{a d v}$ is given by

$$
C_{a d v}=C_{a d} A
$$

Again, the total shortage cost $C_{s h o}$ over the entire cycle is given by

$$
C_{\text {sho }}=c_{b}\left[\left(R-\frac{D(A, p)}{\delta}\right)\left(T-t_{1}\right)+\frac{D(A, p)}{\delta^{2}}\left\{1-e^{-\delta\left(T-t_{1}\right)}\right\}\right]
$$

Total opportunity cost $O C L$ during the entire cycle is given by

$$
O C L=c_{l} D(A, p)\left[\left(T-t_{1}\right)-\frac{1}{\delta}\left\{1-e^{-\delta\left(T-t_{1}\right)}\right\}\right]
$$

The total inventory $\operatorname{cost}(T C)$ of the system is given by

$T C=\langle$ ordering cost $\rangle+\langle$ purchasing cost $\rangle+\langle$ inventory holding cost $\rangle+\langle$ advertisement cost $\rangle+\langle$ transportation cost $\rangle+\langle$ inventory shortage cost $\rangle+\langle$ Opportunity cost $\rangle$

$$
=C_{o}+C_{p}(S+R)+C_{h} \int_{0}^{t_{1}} q(t) d t+C_{a d} A+C_{\text {tran }}+C_{\text {sho }}+O C L
$$

\section{The profit function}

The net profit ( $X$ ) for the entire system is the difference between the sale revenue per cycle and the total cost of the system i.e.,

$$
X=p A^{v}(a-b p) T-T C
$$

Therefore the profit function $Z\left(n, A, t_{1}, T\right)$ (average profit per unit time for the entire cycle) of the inventory system is given by

$$
Z\left(n, A, t_{1}, T\right)=\frac{X}{T}
$$

i.e.,

$$
Z\left(n, A, t_{1}, T\right)=\left[p A^{v}(a-b p)-\left\{C_{4}+C_{3}(S+R)+C_{1} \int_{0}^{t_{1}} q(t) d t+C_{5} A+C_{\text {tran }}+C_{s h o}\right\}\right] / T
$$

Here the profit function is a function of three continuous variables $m, t_{l}, T$ and two integer variables $n, A$. Clearly, the above function is an increasing function with respect to $m$. Hence our problem is to determine the optimal values of $n, A, t_{1}, T$ and $S$ by solving the following mixed integer nonlinear optimization problem.

Maximize $Z\left(n, A, t_{1}, T\right)$

subject to $\mathrm{t}_{1}<T, n, A, t_{1}>0$ and $n, A$ are integers $\}$

where

$$
\begin{aligned}
C_{\text {tran }} & =n C_{t}+(S+R-n k) C_{t f} \text { when } n k<S+R \leq n k+U \\
& =(n+1) C_{t} \quad \text { when } n k+U<S+R \leq(n+1) k
\end{aligned}
$$


An Inventory Model for Deteriorating Items with Non-Linear Selling Price Dependent Demand and Exponentially Partial Backlogging Shortage

The optimal solution of the above problem can be obtained with the help by using GRG method.

\section{Numerical example}

To illustrate the model with partially backlogged shortages, a numerical example with the following data has been considered.

$C_{h}=\$ 0.5$ per unit per unit time, $C_{b}=\$ 3$ per unit per unit time, $C_{p}=\$ 10$ per unit, $C_{o}=\$ 250$ per order, $C_{a d}=\$ 50$ per advertisement, $C_{t}=\$ 100$ per transport vehicle, $C_{t F}=\$ 1.25$ per unit, $\alpha=0.05, \beta=2, \gamma=2, a=200, b=0.4, k=100$ units. $L=50$ $\mathrm{km}, \delta=0.5, v=0.2, c_{l}=10$.

Like first model (no-shortage case), the values of different parameters considered here are realistic, through these are not taken from any case study.

The optimal solution has been obtained with the help of GRG method for different values of $m$. The optimum values of $n, A, t_{1}, T, S$ and $R$ along with maximum average profit are displayed in Table 1.

Table 1: Optimal solution for different values of mark-up rate $m$

\begin{tabular}{|c|c|c|c|c|c|c|c|}
\hline$m$ & $n$ & $A$ & $S$ & $R$ & $t_{1}$ & $T$ & $Z$ \\
\hline 1.20 & 2 & 3 & 249.1748 & 9.459095 & 3.134379 & 3.239685 & 102.6714 \\
\hline 1.25 & 2 & 4 & 264.0838 & 10.77343 & 3.186983 & 3.302367 & 144.8516 \\
\hline 1.30 & 2 & 4 & 260.9001 & 10.55784 & 3.198131 & 3.312978 & 187.7306 \\
\hline 1.35 & 3 & 5 & 273.3519 & 11.80916 & 3.252002 & 3.377038 & 231.1069 \\
\hline 1.40 & 3 & 6 & 284.1465 & 13.01357 & 3.305546 & 3.440684 & 274.5462 \\
\hline
\end{tabular}

\section{Sensitivity analysis}

For the above given example which mentioned earlier, a sensitivity analysis has performed to study the effect of changes of different parameters such as demand, deterioration, inventory cost parameters and mark-up rate an maximum initial stock level, maximum shortage level, cycle length, frequency of advertisement along with the maximum profit of the system. This analysis has been carried out by changing (increasing and decreasing) the parameters from $-20 \%$ to $+20 \%$, taken one or more parameters at a time making the other parameters at their more parameters at a time and making the other parameters at their original values. The results of this analysis are shown in Tables 2.

Table 2: Sensitivity analysis with respect to different parameters respectively for $\mathrm{m}=1.30$

\begin{tabular}{|l|c|c|c|c|c|c|c|}
\hline \multirow{2}{*}{$\begin{array}{l}\text { Param } \\
\text { eter }\end{array}$} & $\begin{array}{c}\text { \% changes of } \\
\text { parameters }\end{array}$ & $\begin{array}{c}\text { changes in } \\
Z^{*}\end{array}$ & $A^{*}$ & \multicolumn{4}{|c|}{ change in } \\
\cline { 5 - 8 } & & & $R^{*}$ & $S^{*}$ & $t_{1}^{*}$ & $T^{*}$ \\
\hline \multirow{3}{*}{$C_{h}$} & -20 & 293.0494 & 6 & 7.147983 & 296.3262 & 3.441484 & 3.514578 \\
\cline { 2 - 8 } & -10 & 283.2320 & 6 & 7.827862 & 290.2666 & 3.374168 & 3.454356 \\
\cline { 2 - 8 } & 10 & 264.4581 & 6 & 9.134675 & 278.9782 & 3.247114 & 3.341008 \\
\cline { 2 - 8 } & 20 & 255.6162 & 5 & 8.763741 & 260.2522 & 3.143647 & 3.237063 \\
\hline
\end{tabular}


M. Golam Arif

\begin{tabular}{|c|c|c|c|c|c|c|c|}
\cline { 2 - 8 } & -20 & 175.1816 & 4 & 8.135646 & 207.0298 & 3.266033 & 3.379959 \\
\cline { 2 - 8 } & -10 & 214.8252 & 5 & 8.954198 & 240.1934 & 3.222276 & 3.328669 \\
\cline { 2 - 8 } & 10 & 297.9600 & 6 & 9.555894 & 294.3700 & 3.117090 & 3.206280 \\
\cline { 2 - 8 } & 20 & 341.1073 & 7 & 10.34144 & 328.8051 & 3.094898 & 3.180616 \\
\hline \multirow{4}{*}{$b$} & -20 & 356.6081 & 7 & 10.25904 & 336.1535 & 3.074381 & 3.156937 \\
\cline { 2 - 8 } & -10 & 302.8004 & 6 & 9.531061 & 296.6894 & 3.109684 & 3.197709 \\
\cline { 2 - 8 } & 10 & 214.7515 & 5 & 8.954522 & 240.1566 & 3.222430 & 3.328848 \\
\hline \multirow{4}{*}{$v$} & 20 & 178.9123 & 4 & 8.120331 & 208.9209 & 3.256746 & 3.369053 \\
\hline & -20 & 163.6026 & 3 & 7.198948 & 188.0141 & 3.244208 & 3.354347 \\
\cline { 2 - 8 } & -10 & 170.3811 & 4 & 8.154974 & 204.5861 & 3.278226 & 3.394292 \\
\cline { 2 - 8 } & 10 & --- & --- & --- & --- & --- & --- \\
\hline \multirow{4}{*}{$C_{O}$} & 20 & 200.8546 & 6 & 9.996173 & 246.2678 & 3.293985 & 3.412843 \\
\cline { 2 - 8 } & -20 & 193.2101 & 5 & 8.059360 & 216.1079 & 3.222583 & 3.329028 \\
\cline { 2 - 8 } & -10 & 186.3893 & 4 & 7.594324 & 206.0525 & 3.213083 & 3.317922 \\
\cline { 2 - 8 } & 10 & --- & --- & --- & --- & --- & --- \\
\hline
\end{tabular}

\section{Concluding remarks}

In this paper, we have described an inventory model for deteriorating items with variable non-linear demand dependent on the selling price and the frequency of advertisement of the item. In practical situations transportation costs of goods/raw material are fixed for a finite capacity of a transport mode such as a truck or other vehicles. A fixed cost is incurred when a truck is deployed whether it is utilized fully or partially for a ceiling quantity or more. For quantities less than the ceiling quantity, a uniform rate per unit is charged.

In this model, the demand rate is taken as $D(A, p)=A^{v} a p^{-b}$. It is well known that $D(A, p) \propto a p^{-b}$ for fixed $A$. But, why should we take $D(A, p) \propto A^{V}$ for fixed values of $p$ ? Generally, the demand of items varies due to the advertisement in the well known media such as Radio, T.V., Newspaper, Magazine, Cinema, etc. The demand of items increases with the increase of frequency of advertisement and is directly proportional to the number of advertisement. Hence, we take $D(A, p) \propto A^{V}$ for fixed $p$.

The problem of inventory and transportation interactions is a potential field of research. We cannot ignore this cost in inventory analysis. The following can be potential problems that can be stated below:

(i) The possibility of single truck supplying the products to more than one stocking point.

(ii) The possibility of inter-depot transportation can be incorporated from the following points of view.

(a) The inventory - distribution costs can be minimized.

(b) This provides another alternative to deal with the space constraint that is operative at some of the stoking point. 
An Inventory Model for Deteriorating Items with Non-Linear Selling Price Dependent Demand and Exponentially Partial Backlogging Shortage

\section{REFERENCES}

1. P.Ghare and G.Schrader, A model for exponential decaying inventories, Journal of Industrial Engineering, 14 (1963) 238-243.

2. H.Emmons, A replenishment model for radioactive nuclide generators, Management Science, 14 (1968) 263-273.

3. R.P.Covert and G.C.Philip, An EOQ model for items with Weibull distribution deterioration, American Institute of Industrial Engineering Transactions, 5 (1973) 323-326.

4. B.C.Giri, A.K.Jalan and K.S.Chaudhuri, Economic order quantity model with weibull deteriorating distribution, shortage and ram-type demand, International Journal of System Science, 34 (2003) 237-243.

5. S.K.Ghosh and K.S.Chaudhury, An order-level inventory model for a deteriorating items with Weibull distribution deterioration, time-quadratic demand and shortages, International Journal of Advanced Modeling and Optimization, 6(1) (2004) 31-45.

6. T.Chakrabarty, B.C.Giri and K.S.Chaudhuri, An EOQ model for items with Weibull distribution deterioration, shortages and trend demand: An extention of Philip's model., Computers \& Operations Research, 25 (1998) 649-657.

7. B.C.Giri, T.Chakrabarty and K.S.Chaudhuri, Retailer's optimal policy for perishable product with shortages when supplier offers all-unit quantity and freight cost discounts, Proceeding of National Academy of Sciences, 69(A) (1999) 315-326.

8. S.Sana, S.K.Goyal and K.S.Chaudhuri, A production-inventory model for a deteriorating item with trended demand and shortages, European Journal of Operation Research, 157 (2004) 357-371.

9. S.Sana and K.S.Chaudhuri, On a volume flexible production policy for deteriorating item with stock-dependent demand rate, Nonlinear Phenomena in Complex System, 7(1) (2004) 61-68.

10. R.B.Misra, Optimum Production lot-size model for a system with deteriorating inventory, International Journal of Production Research, 13 (1975) 495-505.

11. M.Deb and K.S.Chaudhuri, An EOQ model for items with finite rate of production and variable rate of deterioration, Opsearch, 23 (1986) 175-181.

12. B.C.Giri, S.Pal, A.Goswami and K.S.Chaudhuri, An inventory model for deteriorating items with stock-dependent demand rate, European Journal of Operational Research, 95 (1996) 604-610.

13. A.Goswami and K.S.Chaudhuri, An EOQ model for deteriorating items with shortage and a linear trend in demand, Journal of the Operational Research Society, 42 (1991) 1105-1110.

14. B.N.Mandal and S.Phaujdar, An inventory model for deteriorating items and stockdependent consumption rate, Journal of Operational Research Society, 40 (1989) 483-488.

15. G.Padmanabhan and P.Vrat, EOQ models for perishable items under stock-dependent selling rate, European Journal of Operational Research, 86 (1995) 281-292.

16. S.Pal, A.Goswami and K.S.Chaudhuri, A deterministic inventory model for deteriorating items with stock-dependent demand rate, International Journal of Production Economics, 32 (1993) 291-299. 


\section{Golam Arif}

17. M.Mandal and M.Maiti, Inventory model for damageable items with stock-dependent demand and shortages, Opsearch, 34 (1997) 156-166.

18. S.K.Goyal and A.Gunasekaran, An integrated production-inventory-marketing model for deteriorating items, Computers \& Industrial Engineering, 28 (1995) 755-762.

19. B.R.Sarkar, S.Mukherjee and C.V.Balan, An order-level lot-size inventory model with inventory-level dependent demand and deterioration, International Journal of Production Economics, 48 (1997) 227-236.

20. A.K.Bhunia and M.Maiti, Deterministic inventory model for deteriorating items with finite rate of replenishment dependent on inventory level, Computers and Operations Research, 25 (1998) 997-1006.

21. A.K.Bhunia and M.Maiti, An inventory model of deteriorating items with lot-size dependent replenishment cost and a linear trend in demand, Applied Mathematical Modelling, 23 (1998) 301-308.

22. A.K.Bhunia and A.A.Shaikh, A deterministic model for deteriorating items with displayed inventory level dependent demand rate incorporating marketing decision with transportation cost, International Journal of Industrial Engineering Computations, 2(3) (2011) 547-562.

23. A.K.Bhunia and A.A.Shaikh, A two warehouse inventory model for deteriorating items with time dependent partial backlogging and variable demand dependent on marketing strategy and time, International Journal of Inventory Control and Management, 1(2) (2011) 95-110.

24. A.K.Bhunia, A.A.Shaikh, A.K.Maiti and M.Maiti, A two warehouse deterministic inventory model for deteriorating items with linear trend in time dependent demand over finite horizon by Elitist Real-Coded Genetic Algorithm, International Journal of Industrial Engineering Computations, 4(2) (2013) 241-258.

25. A.K.Pal, A.K.Bhunia and R.N.Mukherjee, Optimal lot size model for deteriorating items with demand rate dependent on displayed stock level(DSL) and partial backordering, European Journal of Operational Research, 175 (2006) 977-991.

26. A.K.Bhunia, A.A.Shaikh, S.K.Mahato, C.K.Jaggi, A deteriorating inventory model with displayed stock-level dependent demand and partially backlogged shortages with all unit discount facilities via Particle Swarm Optimization, International Journal of System Science: Operations and Logistics, 1(3) (2014) 164-180.

27. A.K.Bhunia and A.A.Shaikh, A deterministic inventory model for deteriorating items with selling price dependent demand and three-parameter Weibull distributed deterioration, International Journal of Industrial Engineering Computations (Growing Science), 5(3) (2014) 497-510.

28. A.K.Bhunia, A.A.Shaikh, S.Pareek, and V.Dhaka, A memo on stock model with partial backlogging under delay in payments, Uncertain Supply Chain Management, 3(1) (2015) 11-20.

29. P.Kotler, Marketing Decision Making: A Model Building Approach, Holt. Rinehart, Winston, New York (1971).

30. S.Ladany and A.Sternleib, The intersection of economic ordering quantities and marketing policies, AIIE Trnsactions, 6 (1974) 173-175.

31. S.Subramanyam and S.Kumaraswamy, EOQ formula under varying marketing policies and conditions, AIIE Transactions, 22 (1981) 312-314. 
An Inventory Model for Deteriorating Items with Non-Linear Selling Price Dependent Demand and Exponentially Partial Backlogging Shortage

32. T.L.Urban, Deterministic inventory models incorporating marketing decisions, Computers \& Industrial Engineering, 22 (1992) 85-93.

33. P.L.Abad, Optimal pricing and lot-sizing under of conditions of perishability and partial backordering, Management Science, 42 (1996) 1093-1104.

34. W.Luo, An integrated inventory system for perishable goods with backordering, Computers \& Industrial Engineering, 34 (1998) 685-693.

35. A.A.Shaikh, A two warehouse inventory model for deteriorating items with variable demand under alternative trade credit policy, International Journal of Logistics and Systems Management, 27(1) (2017) 40-61.

36. A.K.Bhunia, A.A.Shaikh and R.K.Gupta, A study on two warehouse partially backlogged deteriorating inventory models under inflation via particle swarm optimization, International Journal of System Science, 46(6) (2015) 1036-1050.

37. A.K.Bhunia, A.A.Shaikh and L.Sahoo, A two-warehouse inventory model for deteriorating items under permissible delay in payment via particle swarm optimization, International Journal of Logistics and Systems Management, 24(1) (2015) 45-68.

38. A.K.Bhunia, A.A.Shaikh, G.Sharma and S.Pareek, A two storage inventory model for deteriorating items with variable demand and partial backlogging, Journal of Industrial and Production Engineering, 32(4) (2015) 263-272.

39. A.K.Bhunia, A.A.Shaikh, V.Dhaka and S.Pareek, An application of Genetic Algorithm and PSO in an inventory model for single deteriorating item with variable demand dependent on marketing strategy and displayed stock level, Scientica Iranica (in press) (2017).

40. A.K.Bhunia, A.A.Shaikh, Investigation of two-warehouse inventory problems in interval environment under inflation via particle swarm Optimization, Mathematical and Computer Modelling of Dynamical Systems, 22 (2) (2016) 160-179.

41. A.A.Shaikh, Md.Masud, Md.Uddin, A.A.Khan, Non instantaneous deterioration inventory model with price and stock dependent demand for fully backlogged shortages under inflation, International Journal of Business Forecasting and Marketing Intelligence (in press) (2017).

42. A.A.Shaikh, L.E.Cardenas-Barron, A.K.Bhunia and S.Tiwari, An inventory model of a three parameter Weibull distributed deteriorating item with variable demand dependent on price and frequency of advertisement under trade credit, RairoOperations research Journal (in press) (2017).

43. A.A.Shaikh, L.E.Cardenas-Barron and S.Tiwari, A two-warehouse inventory model for non-instantaneous deteriorating items with interval valued inventory costs and stock dependent demand under inflationary conditions, Neural Computing and Applications (in press) (2017).

44. A.A.Shaikh, G.C.Panda, S.Sahu and A.K.Das, Economic order quantity model for deteriorating item with preservation technology in time dependent demand with partial backlogging and trade credit, International Journal of Logistics and Systems Management, (in press) (2017).

45. A.K.Bhunia, A.A.Shaikh and L.E.Cardenas-Barron, A partially integrated production inventory model with interval valued inventory costs, variable demand and flexible reliability, Applied Soft Computing, 55 (2017) 491-502. 


\section{Golam Arif}

46. S.Tiwari, C.K.Jaggi, A.K.Bhunia and A.A.Shaikh, A two warehouse inventory model for non-instantaneous deteriorating items with stock dependent demand under inflationary conditions using particle swarm optimization, Annals of Operational Research (in press).

47. U.Mishra, L.E.Cardenas-Barron, S.Tivari, A.A.Shaikh and T.G.Gererdo, An inventory model under price and stock dependent demand for controllable deterioration rate with shortages and preservation technology investment, Annals of Operational Research, 254 (1-2) (2017) 150-190.

48. S.Chakraborty, M.Pal and P.K.Nayak, Solution of interval-valued manufacturing inventory models with shortages, International J. of Engineering and Physical Sciences, 4(2) (2010) 96-101.

49. S.Chakraborty, M.Pal and P.K.Nayak, Multisection technique to solve intervalvalued purchasing inventory models without shortages, Journal of Information and Computing Science, 5(3), (2010) 173-182.

50. S.Chakraborty, M.Pal and P.K.Nayak, Intuitionistic fuzzy optimization technique for the solution of an EOQ model, Notes on Intuitionistic Fuzzy Sets, 17(2) (2011) 5264.

51. S.Chakraborty, M.Pal and P.K.Nayak, Intuitionistic fuzzy optimization technique for pareto optimal solution of manufacturing inventory models with shortages, European Journal of Operational Research, 228 (2013) 381-387.

52. S.Chakraborty, M.Pal and P.K.Nayak, An algorithm for solution of an interval valued EOQ model, Int. J. Optimization and Control: Theories \& Applications, 3(1) (2013) $55-64$. 